\title{
Phytophthora cactorum can synthesize substances needed for sexual reproduction but requires a stress factor to trigger the process
}

\author{
Hyeong-Jin Jee $†$ and Wen-Hsiung Ko
}

Author for correspondence: Wen-Hsiung Ko. Tel: +1 808974 4105. Fax: +1 8089744110.

Department of Plant Pathology, Beaumont Agricultural Research Center, University of Hawaii at Manoa, Hilo, Hawaii 96720, USA

\begin{abstract}
Phytophthora cactorum grown on basal agarose medium or in liquid basal medium produced oospores after being transferred to water agarose. The numbers of oospores produced under such conditions depended on the age of the culture prior to exposure to nutrient deprivation. When the concentration of basal medium used for cultivation of $P$. cactorum was increased, the numbers of oospores produced after being transferred to water agarose was also increased. $P$. cactorum grown on basal agarose medium also produced oospores when its mycelial growth was restricted after reaching the edge of Petri plates. In $5 \mathrm{~cm}$ plates oospore formation occurred in the third week, whereas in $9 \mathrm{~cm}$ and $14 \mathrm{~cm}$ plates oospores appeared in the fourth week. Most oospores were formed near the edge of the plates. The non-saponifiables extracted from mycelia of $P$. cactorum grown in liquid basal medium were stimulatory to oospore formation by $P$. cactorum and Phytophthora parasitica, whereas the saponifiables were stimulatory to $P$. cactorum only. Extracts from culture filtrate and basal medium were not stimulatory to oospore formation by either fungus. When the non-saponifiables were fractionated by Florisil columm chromatography, only fraction 1 was not active. Fractions 2, 3 and 4 were stimulatory to oospore formation by both $P$. cactorum and $P$. parasitica. These results support the hypothesis that $P$. cactorum, and possibly other pythiaceous fungi as well, can synthesize substances needed for sexual reproduction but requires a stress factor to trigger the process.
\end{abstract}

Keywords: Phytophthora cactorum, basal medium, stimulatory substances, sexual reproduction, stress factors

\section{INTRODUCTION}

Sterols were originally considered to be required for sexual reproduction in pythiaceous fungi and Phytophthora cactorum (Lebert \& Cohn) Schroeter was the most commonly used organism in such studies (Elliott, 1983). This finding was accompanied by the discovery of the inability of this group of fungi to synthesize sterols (Hendrix, 1970; Elliott, 1983). However, it was subsequently found that sterols are stimulatory but not essential for sexual reproduction in P. cactorum because stimulatory effects can also be caused by phospholipids (Ko, 1985; Ko \& Ho, 1983). Furthermore, sterols were not able to stimulate sexual reproduction of Phytoph-

†Present address: Division of Plant Pathology, National Institute of Agricultural Science and Technology, Suwon 441-707, Korea.

Abbreviation: FCC, Florisil column chromotography. thora parasitica Daster and Phytophthora capsici Leonian, which were stimulated by lecithins (Ko, 1985; Ko \& Ho, 1983). Sexual reproduction of Pythium aphanidermatum (Edson) Fitzpatrick was also stimulated by some glycerides such as dipalmitin (Ko, 1986). Recently, it was found that after removal of contaminants by aminopropyl column chromatography the stimulatory activity of phospholipids was greatly increased (Jee et al., 1997). These contaminants were isolated and shown to be inhibitory to oospore formation by P. cactorum. After removal of the inhibitory substances, most of the highly purified commercial fatty acids and related compounds became stimulatory to sexual reproduction of P. cactorum (Jee \& Ko, 1997).

Although incapable of synthesizing sterols, pythiaceous fungi are known to be able to synthesize various types of terpenoids, fatty acids, phospholipids and other lipid compounds (Losel, 1988). Phytophthora cinnamomi has 
been shown to be capable of synthesizing geraniol and squalene from acetate (Wood \& Gottlieb, 1978a, b). Synthesis of phospholipids, including lecithin and cephalin, by $P$. parasitica, and synthesis of fatty acids by $P$. cactorum have been reported by Hendrix \& Rouser (1976) and Nes (1988), respectively. Pythium ultimum has also been reported to synthesize lecithin, cephalin and fatty acids (Bowman \& Mumma, 1967). Since these compounds are all stimulatory to sexual reproduction of P. cactorum (Jee \& Ko, 1997), it was considered possible that $P$. cactorum and possibly other pythiaceous fungi are capable of synthesizing substances needed for their own sexual reproduction and that a certain stress factor is needed to trigger this sexual process in these fungi growing on basal medium.

In this study, various stress factors were tested for their ability to induce oospore formation by $P$. cactorum on basal medium and extracts from mycelia of the fungus grown in liquid basal medium were tested for their ability to support oospore formation to determine if the hypothesis was correct.

\section{METHODS}

Organisms. Isolates of $P$. cactorum and $P$. parasitica and the basal medium used in this study were described in a previous paper (Jee et al., 1997). Cultures continuously maintained on basal agarose (SeaKem HGT-P Agarose, FMC, BioProducts) medium were used as the source of inoculum. Under such conditions, a single isolate of $P$. cactorum or paired A1 and A2 isolates of $P$. parasitica did not form oospores on the basal medium unless a stimulatory substance such as lecithin was added, indicating that stimulatory substances had not been carried over from the original inoculum (Jee et al., 1997).

Stress factors. Culture discs (12 mm diameter, $5 \mathrm{~mm}$ thick) obtained from a 7-d-old culture established on basal agarose medium as described above were individually subjected to the following stress factors: (i) nutrient deprivation by placing the disc in an empty Petri plate, or Petri plate containing $25 \mathrm{ml}$ sterile distilled water or water agarose $(0 \cdot 8 \%$ SeaKem HGT-P agarose) (Ho \& Ko, 1980); (ii) high osmotic pressure by placing the disc on basal agarose medium amended with 1000 p.p.m. KCl; (iii) growth retardation by placing the disc on basal agarose medium amended with 10 p.p.m. metalaxyl (Subdue 2E, 25.11\% active ingredient) or 150 p.p.m. streptomycin sulfate. After incubation for $7 \mathrm{~d}$ at $24^{\circ} \mathrm{C}$ in darkness in a moist chamber, oospores were counted directly under a microscope. To obtain mycelial mats for similar tests, each $250 \mathrm{ml}$ flask containing $25 \mathrm{ml}$ liquid basal medium was inoculated with 10 pieces (approx. $2 \times 2 \times 5 \mathrm{~mm}$ ) of $P$. cactorum culture established on basal agarose medium. After incubation for $7 \mathrm{~d}$ at $24^{\circ} \mathrm{C}$, the mycelial mats were picked up with a pair of forceps, washed in $25 \mathrm{ml}$ sterile distilled water, transferred to tilted empty Petri plates to drain off free water and exposed to the same stress factors as described above. After incubation for $7 \mathrm{~d}$ at $24^{\circ} \mathrm{C}$, cultures containing oospores in Petri plates were ground with $30 \mathrm{ml}$ distilled water in an Omni mixer at 4000 r.p.m. for 1 min. Oospore concentration in the suspension was determined with a microlitre pipette (Ko et al., 1973). Only normal oospores were counted. Immature or aborted oospores were excluded. Three replicates were used for each treatment and all experiments were repeated with an independent batch of medium at least once.
Extraction of stimulatory substances from mycelia. Two plates of 14-d-old P. cactorum culture grown on basal agarose medium were triturated with $100 \mathrm{ml}$ sterile distilled water in a sterilized Omni mixer at 4000 r.p.m. for 1 min. One millilitre of the culture suspension was added to a $250 \mathrm{ml}$ flask containing $50 \mathrm{ml}$ double strength liquid basal medium. After incubation for $14 \mathrm{~d}$ at $24^{\circ} \mathrm{C}$ in darkness, mycelia in $100 \mathrm{ml}$ flasks were harvested by filtration through Whatman no. 541 filter paper, washed with $200 \mathrm{ml}$ distilled water and dried overnight at $60^{\circ} \mathrm{C}$. About $11.7 \mathrm{~g}$ dried mycelia was ground in a mortar and added to a $500 \mathrm{ml}$ boiling flask containing $210 \mathrm{ml}$ $95 \%(\mathrm{v} / \mathrm{v})$ ethanol and $35 \mathrm{ml} 50 \%(\mathrm{w} / \mathrm{v}) \mathrm{KOH}$. After gentle boiling under a reflux condenser for $2 \mathrm{~h}$, the mixture was adjusted to $500 \mathrm{ml}$ with deionized water. Non-saponifiables were extracted from the mixture by three aliquots of $35 \mathrm{ml}$ petroleum ether (American Oil Chemists' Society, 1971). The saponifiable fraction was obtained by adjusting the aqueous portion to $\mathrm{pH} 2$ with $6 \mathrm{M} \mathrm{HCl}$ and extracting the acidified solution with petroleum ether. Both non-saponifiable and saponifiable fractions were evaporated and the residues were dissolved in $1 \mathrm{ml}$ ethyl acetate for bioassay.

The method previously described (Jee et al., 1997) was used for the bioassays. Six basal medium discs (12 mm diameter, $5 \mathrm{~mm}$ thick) were evenly distributed in a Petri plate and $10 \mu \mathrm{l}$ ethyl acetate solution containing 10 or $100 \mu \mathrm{g}$ mycelial extract was spread over their surfaces. After evaporation of the ethyl acetate in a fume hood for $10 \mathrm{~min}$, the discs were inoculated with a small piece of $P$. cactorum culture or pieces of A1 and A2 $P$. parasitica cultures about $2-3 \mathrm{~mm}$ away from each other. Inoculated discs were incubated for $7 \mathrm{~d}$ at $24^{\circ} \mathrm{C}$ in darkness in a moist chamber for oospore formation. The number of oospores produced was determined as described above.

Florisil column chromatography (FCC). Chromatography of the non-saponifiables on Florisil (60-100 mesh, 500 g, Fisher Scientific) was performed following the method of Carroll (1961). Thirty grams Florisil was packed in a column $(2 \times 30 \mathrm{~cm})$ with $60 \mathrm{ml}$ hexane. Excess hexane was drained from the bottom before $70 \mathrm{mg}$ non-saponifiables in $2 \mathrm{ml}$ hexane was loaded on the top of the Florisil in the column. The column was washed with eluting solvents in the following order : $60 \mathrm{ml}$ hexane, $200 \mathrm{ml} 5 \%(\mathrm{v} / \mathrm{v})$ ether in hexane, $200 \mathrm{ml}$ $25 \%(\mathrm{v} / \mathrm{v})$ ether in hexane and $360 \mathrm{ml} 2 \%(\mathrm{v} / \mathrm{v})$ methanol in ether.

\section{RESULTS}

\section{Effect of stress factors on oospore formation on basal medium}

Among the various stress treatments tested, only exposure to nutrient deprivation by transfer of culture to water agarose was effective in inducing oospore formation by $P$. cactorum grown in basal agarose medium or liquid basal medium. The numbers of oospores produced by the fungus grown in solid and liquid media were $82.7 \pm 9.8$ and $31.6 \pm 4.2 \mathrm{ml}^{-1}$, respectively. After being transferred, $P$. cactorum grew sparingly from culture discs or mycelial mats and produced oospores in water agarose. Incubation of culture discs or mycelial mats in water or on basal agarose medium containing inhibitors or high concentrations of salts was not effective. Exposure of culture discs or mycelial mats to 4 or $36^{\circ} \mathrm{C}$ for $24 \mathrm{~h}$, or to air drying in a transfer hood for $6 \mathrm{~h}$ before being transferred to basal agarose medium also failed to induce oospore formation (data not 
Table 1. Effect of culture age of $P$. cactorum grown on solid or liquid basal medium on oospore formation following transfer to water agarose

\begin{tabular}{|ccc|}
\hline Culture age (d) & \multicolumn{2}{c|}{ No. oospores $(\mathrm{ml} \text { medium })^{-1} \pm S D$} \\
\cline { 2 - 3 } & Solid medium & Liquid medium \\
\hline 7 & $86 \cdot 0 \pm 10 \cdot 9$ & $33 \cdot 7 \pm 3 \cdot 4$ \\
14 & $62 \cdot 3 \pm 7 \cdot 2$ & $99 \cdot 2 \pm 14 \cdot 5$ \\
21 & $38 \cdot 0 \pm 7 \cdot 2$ & $73 \cdot 5 \pm 7 \cdot 6$ \\
28 & $29 \cdot 3 \pm 4 \cdot 2$ & $50 \cdot 5 \pm 7 \cdot 1$ \\
42 & $29 \cdot 3 \pm 4 \cdot 3$ & $35 \cdot 1 \pm 4 \cdot 1$ \\
\hline
\end{tabular}

Table 2. Effect of the concentration of basal medium on oospore formation by $P$. cactorum $7 \mathrm{~d}$ after transfer to water agarose

\begin{tabular}{|lcc|}
\hline $\begin{array}{l}\text { Concentration of } \\
\text { basal medium }\end{array}$ & \multicolumn{2}{c|}{ No. oospores $(\mathrm{ml} \text { medium })^{-1} \pm S D$} \\
\cline { 2 - 3 } & Solid medium & Liquid medium \\
\hline Half & $19 \cdot 7 \pm 1 \cdot 7$ & $11 \cdot 0 \pm 2 \cdot 2$ \\
Standard & $88 \cdot 3 \pm 13 \cdot 7$ & $42 \cdot 4 \pm 7 \cdot 7$ \\
Double & $144 \cdot 6 \pm 16 \cdot 7$ & $77 \cdot 7 \pm 10 \cdot 1$ \\
\hline
\end{tabular}

shown). P. cactorum also did not form oospores when culture discs or mycelial mats on basal agarose were incubated at 4 or $36^{\circ} \mathrm{C}$ (data not shown).

\section{Factors affecting oospore formation on basal medium induced by nutrient deprivation}

To study the effect of culture age on oospore formation, culture discs and mycelial mats were obtained, respectively, from basal agarose medium and liquid basal medium inoculated with $P$. cactorum and incubated at $24^{\circ} \mathrm{C}$ for $7,14,21,28$ and $42 \mathrm{~d}$. They were then transferred to water agarose for induction of oospore formation. For cultures grown on basal agarose medium, the optimum age for oospore production was $7 \mathrm{~d}$ (Table 1). Thereafter, the numbers of oospores produced decreased with increasing age of culture up to $28 \mathrm{~d}$. There was no difference in the numbers of oospores produced by 28 and $42 \mathrm{~d}$ cultures. For cultures grown on liquid basal medium, the optimum age for oospore production was $14 \mathrm{~d}$. Thereafter, the numbers of oospores produced decreased with increasing age of culture up to the oldest tested (Table 1).P. cactorum was also cultured on basal agarose medium or in liquid basal medium containing half, standard or double strength ingredients for $7 \mathrm{~d}$ before being transferred to water agarose for induction of oospore formation. The numbers of oospores produced increased when the concentration of nutrients increased in both cases (Table 2). In a separate test, mycelia growing in flasks containing different nutrient concentrations (one flask for each concentration) were dried at $60^{\circ} \mathrm{C}$ overnight after $7 \mathrm{~d}$ incubation at $24^{\circ} \mathrm{C}$. The mycelial mat from standard
Table 3. Oospore formation in $P$. cactorum on basal agarose medium in different sized Petri plates

The amounts of medium in $5 \mathrm{~cm}, 9 \mathrm{~cm}$ and $14 \mathrm{~cm}$ plates were 10,25 and $60 \mathrm{ml}$, respectively. No oospores were formed after 1 or 2 weeks incubation.

\begin{tabular}{|c|c|c|c|}
\hline \multirow{2}{*}{$\begin{array}{l}\text { Incubation time } \\
\text { (weeks) } \\
\text { Plate diameter } \\
\qquad(\mathrm{cm}) . .\end{array}$} & \multicolumn{3}{|c|}{ No. oospores per plate $\pm S D$} \\
\hline & 5 & 9 & 14 \\
\hline 3 & $46 \pm 91$ & 0 & 0 \\
\hline 4 & $1133 \pm 301$ & $1420 \pm 250$ & $4386 \pm 660$ \\
\hline 6 & $1150 \pm 405$ & $2760 \pm 502$ & $17802 \pm 2394$ \\
\hline
\end{tabular}

Table 4. Effect of the amount of basal agarose medium on oospore formation by $P$. cactorum in $5 \mathrm{~cm}$ Petri plates

No oospores were formed after 1 or 2 weeks incubation.

\begin{tabular}{|c|c|c|c|}
\hline \multirow{2}{*}{$\begin{array}{l}\text { Incubation time } \\
\text { (weeks) } \\
\text { Amount of } \\
\text { medium (ml) ... }\end{array}$} & \multicolumn{3}{|c|}{ No. oospores per plate $\pm S D$} \\
\hline & 5 & 10 & 15 \\
\hline 3 & $413 \pm 106$ & $1160 \pm 245$ & $1556 \pm 210$ \\
\hline 4 & $560 \pm 106$ & $1406 \pm 160$ & $1637 \pm 213$ \\
\hline 6 & $622 \pm 123$ & $1520 \pm 433$ & $3560 \pm 1470$ \\
\hline
\end{tabular}

medium weighed about $1.45 \mathrm{mg}$. When the nutrient concentration in liquid basal medium decreased to half of the standard level, the dry weight of mycelia was decreased about 3.3 times. When the nutrient concentration was doubled, the dry weight of mycelia was increased about 1.7 times (results not shown).

\section{Oospore formation on basal medium induced by growth limitation}

Inoculum discs ( $5 \mathrm{~mm}$ diameter) of $P$. cactorum grown on basal medium were placed in the centre of 5,9 and $14 \mathrm{~cm}$ Petri plates containing 10, 25 and $60 \mathrm{ml}$ basal medium, respectively. Plates were observed under a microscope every week and oospores were counted for 6 weeks as described previously. Mycelia of P. cactorum reached the edge of $5 \mathrm{~cm}$ plates in 2 weeks, and that of 9 and $14 \mathrm{~cm}$ plates in 3 weeks.

During the growth period, no oospores were produced. However, oospores started to appear within 1 week after mycelia reached the edge of plates (Table 3 ). The larger the size of plates used, the larger the number of oospores produced.

To determine the relationship between the amount of basal medium used and the number of oospores produced, $5 \mathrm{~cm}$ plates each containing 5,10 or $15 \mathrm{ml}$ basal medium were inoculated with $P$. cactorum as described 
Table 5. Activity of non-saponifiables of mycelial extract of $P$. cactorum on oospore formation by $P$. cactorum and $P$. parasitica following FCC

\begin{tabular}{|c|c|c|c|c|c|}
\hline \multirow[t]{2}{*}{ Fraction } & \multirow{2}{*}{$\begin{array}{l}\text { Eluting } \\
\text { solvent }\end{array}$} & \multirow{2}{*}{$\begin{array}{l}\text { Lipid class } \\
\text { eluted }\end{array}$} & \multirow{2}{*}{$\begin{array}{c}\text { Recovery } \\
(\%)\end{array}$} & \multicolumn{2}{|c|}{ No. oospores $(10 \mu \mathrm{g} \text { sample })^{-1} \pm \mathrm{SD}$} \\
\hline & & & & P. cactorum & P. parasitica \\
\hline 1 & Hexane $(60 \mathrm{ml})$ & Hydrocarbons & $1 \cdot 2$ & 0 & 0 \\
\hline 2 & $\begin{array}{l}5 \% \text { ether in hexane } \\
(200 \mathrm{ml})\end{array}$ & Sterol esters & $3 \cdot 8$ & $9875 \pm 1540$ & $5750 \pm 957$ \\
\hline 3 & $\begin{array}{l}25 \% \text { ether in hexane } \\
(200 \mathrm{ml})\end{array}$ & Sterol, triglycerides & $12 \cdot 5$ & $46875 \pm 5105$ & $11250 \pm 645$ \\
\hline 4 & $\begin{array}{l}2 \% \text { methanol in } \\
\text { ether }(360 \mathrm{ml})\end{array}$ & Mono-, diglycerides & $82 \cdot 5$ & $4875 \pm 1875$ & $76 \pm 35$ \\
\hline
\end{tabular}

above. The fungus started to produce oospores after the mycelia reached the edge of the plates regardless of the amount of basal medium used (Table 4). The more the basal medium present in a plate, the more the oospores produced.

To determine the distribution of oospores on water agarose, $5 \mathrm{~cm}$ plates each containing $10 \mathrm{ml}$ basal medium were inoculated with $P$. cactorum as described above. Most oospores were produced near the edge of the plates. The numbers of oospores produced near the centre, between the centre and the edge and near the edge were $3.7 \pm 0.6,24.0 \pm 5.0$ and $166.2 \pm 30.5 \mathrm{ml}^{-1}$, respectively.

\section{Stimulation of oospore formation by substances extracted from mycelia}

The non-saponifiables extracted from mycelia of $P$. cactorum grown in liquid basal medium were stimulatory to oospore formation by $P$. cactorum and $P$. parasitica $[18250 \pm 1779$ and $10510 \pm 1472$ oospores $(100 \mu \mathrm{g} \text { sample })^{-1}$, respectively, after incubation for $7 \mathrm{~d}$ at $24^{\circ} \mathrm{C}$ in darkness], whilst the saponifiables were stimulatory to $P$. cactorum only [5277 \pm 745 oospores $\left.(100 \mu \mathrm{g} \text { sample })^{-1}\right]$. Extracts from culture filtrate and liquid basal medium were not stimulatory to oospore formation by either fungus. When the non-saponifiables from mycelia were fractionated by FCC, fraction 4 contained the largest amount of the components followed by FCC fractions 3, 2 and 1 (Table 5). Only FCC fraction 1 was not active. The other fractions were stimulatory to oospore formation by both $P$. cactorum and $P$. parasitica. FCC fraction 3 was most active followed by FCC fractions 2 and 4.

\section{DISCUSSION}

In this study, it was found that the extract from mycelia of $P$. cactorum grown in liquid basal medium was stimulatory to oospore formation by both $P$. cactorum and $P$. parasitica. P. cactorum also produced oospores on basal medium when it was transferred to the nutrientfree solid medium of water agarose (Ho \& Ko, 1980) or when its growth was limited after reaching the edge of culture plates. These results support the hypothesis that
P. cactorum, and possibly other pythiaceous fungi as well, can synthesize substances needed for sexual reproduction but requires a stress factor to trigger the process.

When the concentration of basal medium used for culture of $P$. cactorum was increased, the numbers of oospores produced after being transferred to water agarose was also increased. This suggests that the amount of stimulatory substances synthesized is positively correlated with the amount of basal nutrients available. When basal-medium-grown cultures of $P$. cactorum were transferred to sterile distilled water, the fungus did not continue to grow and no oospores were produced. This suggests that new growth is needed for oospore formation and that nutrient stress created by diffusion gradients in water (Ko \& Lockwood, 1967) is too strong to be suitable for initiation of sexual reproduction.

Induction of sexual reproduction in $P$. cactorum by growth limitation appears to be a relatively slow process because in $9 \mathrm{~cm}$ plates the fungus formed oospores in the fourth but not third week of incubation. Most researchers recorded their observations of induction of sexual reproduction in $P$. cactorum within 1 or 2 weeks (Elliott et al., 1964; Harnish, 1968; Leal et al., 1964). This may explain why oospore formation by pythiaceous fungi in basal medium has not been reported previously.

The non-saponifiables in mycelial extracts of $P$. cactorum were stimulatory to oospore formation by $P$. cactorum and $P$. parasitica, whilst the saponifiables were stimulatory only to $P$. cactorum. This result suggests that at least two different kinds of stimulatory substances were synthesized by P. cactorum. Moreover, different FCC fractions of the non-saponifiables showed differences in ability to support oospore formation by $P$. cactorum and $P$. parasitica, indicating that there is more than one non-saponifiable stimulatory substance existing in the mycelial extract. The identity of these compounds remains to be investigated. The activity of stimulatory substances extracted from mycelia of $P$. cactorum was comparable to that of fatty acids and related compounds tested by Jee \& Ko (1997). 


\section{REFERENCES}

American Oil Chemists' Society (1971). Sampling and analysis of commercial fats and oils. A.O.C.S. Official Method Ca 6a-40. In Official and Tentative Methods of the American Oil Chemists' Society, 3rd edn. Chicago: The American Oil Chemists' Society.

Bowman, R. D. \& Mumma, R. O. (1967). The lipids of Pythium ultimum. Biochim Biophys Acta 144, 501-510.

Carroll, K. K. (1961). Separation of lipid classes by chromatography on Florisil. J Lipid Res 2, 135-141.

Elliott, C. G. (1983). Physiology of sexual reproduction in Phytophthora. In Phytophthora: its Biology, Taxonomy, Ecology, and Pathology, pp. 71-88. Edited by D. C. Erwin, S. Bartnicki-Garcia \& P. H. Tsao. St Paul, MN: American Phytopathological Society.

Elliott, C. G., Hendrie, M. E., Knight, G. A. \& Parker, W. (1964). A steroid growth factor requirement in a fungus. Nature 203, 427-428.

Harnish, W. N. (1968). Effect of sterols in sexual reproduction of Phytophthora cactorum. Proc W Va Acad Sci 40, 99-104.

Hendrix, J. W. (1970). Sterols in growth and reproduction of fungi. Annu Rev Pbytopathol 8, 111-130.

Hendrix, J. W. \& Rouser, G. (1976). Polar lipids of Phytophthora parasitica var. nicotianae in comparison with those of selected other fungi. Mycologia 68, 354-361.

Ho, W. C. \& Ko, W. H. (1980). Agarose medium for bioassay of antimicrobial substances. Phytopathology 70, 764-766.

Jee, H. J. \& Ko, W. H. (1997). Stimulation of sexual reproduction of Phytophthora cactorum and $P$. parasitica by fatty acids and related compounds. Mycol Res 101, 1140-1144.

Jee, H.-J., Tang, C.-S. \& Ko, W.-H. (1997). Stimulation of sexual reproduction in Phytophthora cactorum by phospholipids is not due to sterol contamination. Microbiology 143, 1631-1638.
Ko, W. H. (1985). Stimulation of sexual reproduction of Phytophthora cactorum by phospholipids. J Gen Microbiol 131, 2591-2594.

Ko, W. H. (1986). Sexual reproduction of Pythium aphanidermatum: stimulation by phospholipids. Phytopathology 76, 1159-1160.

Ko, W. H. \& Ho, W. C. (1983). Reassessment of apparent sterol requirement for sexual reproduction in Phytophthora. Ann Phytopathol Soc Jpn 49, 316-321.

Ko, W. H. \& Lockwood, J. L. (1967). Soil fungistasis: relation to fungal spore nutrition. Phytopathology 57, 894-901.

Ko, W. H., Chase, L. L. \& Kunimoto, R. K. (1973). A microsyringe method for determining concentration of fungal propagules. Phytopathology 63, 1206-1207.

Leal, J. A., Friend, J. \& Holliday, P. (1964). A factor controlling sexual reproduction in Phytophthora. Nature 203, 545-546.

Losel, D. M. (1988). Fungal lipids. In Microbial Lipids, vol. 1, pp. 699-806. Edited by C. Ratledge \& S. G. Wilkinson. London: Academic Press.

Nes, W. D. (1988). Phytophthorols - novel lipids produced by Phytophthora cactorum. Lipids 23, 9-16.

Wood, S. G. \& Gottlieb, D. (1978a). Evidence from mycelial studies for differences in the sterol biosynthetic pathway of Rhizoctonia solani and Phytophthora cinnamomi. Biochem J 170, 343-354.

Wood, S. G. \& Gottlieb, D. (1978b). Evidence from cell free systems for differences in the sterol biosynthetic pathway of Rhizoctonia solani and Phytophthora cinnamomi. Biochem J170, 355-363.

Received 8 May 1997; revised 4 December 1997; accepted 12 December 1997. 